\title{
Mathematical Modeling Of Magnetic Scaffolds For Targeted Drug Delivery And Bone Repair
}

This paper was downloaded from TechRxiv (https://www.techrxiv.org).

LICENSE

CC BY 4.0

SUBMISSION DATE / POSTED DATE

31-08-2021 / 01-09-2021

\section{CITATION}

Lodi, Matteo Bruno; Fanti, Alessandro; Vargiu, Andrea; Bozzi, Maurizio; Mazzarella, Giuseppe (2021): Mathematical Modeling Of Magnetic Scaffolds For Targeted Drug Delivery And Bone Repair. TechRxiv. Preprint. https://doi.org/10.36227/techrxiv.16545669.v1

$\mathrm{DOI}$

10.36227/techrxiv.16545669.v1 
This work has been submitted to the IEEE for possible publication.

Copyright may be transferred without notice, after which this version may no longer be accessible 


\title{
MATHEMATiCAL Modeling OF MAGNETIC SCAFFOLDS FOR TARGETED DRUG DELIVERY AND BONE REPAIR
}

\author{
Matteo B. Lodi, Student Member, IEEE, Alessandro Fanti, Member, IEEE, Andrea Vargiu, \\ Maurizio Bozzi, Fellow, IEEE, Giuseppe Mazzarella, Senior Member, IEEE
}

\begin{abstract}
Magnetic bone substitutes are multifunctional nanocomposite biomaterials designed to serve as an in situ attraction platform for magnetic carriers of growth factors. The morphological and functional properties of these biomaterials were characterized so far, but very little is known on the treatment dynamics, and the latter cannot be designed from an engineering point of view. For the first time, this work deals with the mathematical modeling of the use of magnetic scaffolds and functionalized nanoparticles to evaluate the enhancement of osteogenesis and bone repair. The non-linear magnetization of the scaffolds is considered to simulate the attraction and transport of magnetic nanoparticles. Different biomaterials and drug carriers from the literature are analyzed. The drug release via RF-heating is modeled considering the multiphysics nature of the phenomena. The physiological process of bone healing is reproduced using nine non-linear equations. The influence of the delivered growth factor on osteogenesis is assessed and quantified in silico, while compared to numerical simulations of intravenous injection of growth factor and to its release from the biomaterial. The exploitation of magnetic carriers of biomolecules with magnetic scaffolds allows to produce a more homogeneous and uniform distribution of mature bone, overcoming the limitation of traditional drug delivery techniques.
\end{abstract}

Keywords - Biomagnetics, magnetic scaffolds, magnetic particles, tissue engineering, targeted drug delivery

\section{INTRODUCTION}

$\mathrm{T}$ HE goal of bone tissue engineering is the development of tools capable of favoring and selectively elicit the physiological process of bone healing to repair or regenerate an injured area [1], [2]. Such tools are called scaffolds and are polymeric or ceramic objects to be implanted in a damaged tissue [1]. Bone scaffolds use exogenous and/or extrinsic factors to induce a therapeutic action to facilitate the healing process [3], [4]. Their first function is structural: they withstand the injured tissue during its healing [5]. However, scaffolds should be designed to establish conditions to favor the mesenchymal stem cells (MSCs) migration, adhesion, and differentiation [4]-[6]. Many research efforts have been spent to turn bone scaffolds into functional objects capable of minimizing tissue rejection and the inflammatory response. This allows a better, faster integration of the prosthetic implants by eliciting specific physical or biological processes fundamental for bone repair and regeneration [1]-[6]. Scaffolds with an optimized nanostructured surface topography as a vehicle for mechanobiological stimulation

M. B. Lodi, A. Fanti, A. Vargiu and G. Mazzarella are with the Department of Electrical and Electronic Engineering, University of Cagliari, Cagliari 09123 Italy, e-mails: matteob.lodi@unica.it; alessandro.fanti@diee.unica.it; $\quad$ andvar95@gmail.com; mazzarella@diee.unica.it.

M. Bozzi is with the Department of Electrical, Computer and Biomedical Engineering, University of Pavia, 27100 Pavia, Italy (e-mail: maurizio.bozzi@unipv.it) to the intracellular structures are thoroughly investigated [7], [8]. Other researchers manufactured implants which provided external cues to bone regeneration by embedding ionic species (e.g., $\mathrm{Ca}^{+}, \mathrm{Ag}^{+}, \mathrm{Cu}^{+}$) or growth factors (GFs) [9]. Hence the scaffold itself may constitutes a local drug delivery system. However, traditional drug-loaded scaffolds are associated with burst release, scarce spatial control and impossibility of reloading [6]. These limitations have led to the investigation of the bone scaffold functionalized with magnetic nanoparticles (MNPs) to obtain a remotely controlled functional device [10]-[14]. A so-called magnetic scaffold (MagS) is a nanocomposite material with strong saturation magnetization $\left(2.5-100 \mathrm{kAm}^{-1}\right)$, implanted in the injured bone and can be exploited as an in situ magnet able to control and enhance the magnetic drug delivery (MDD) of growth factors to the defect site [12][14].

MDD systems triggered by thermal release are studied [15], [16]. Recently, Monsalve et al. manufactured a poly(ethylene glycol)-coated iron oxide nanoparticles with Transforming Growth Factor- $\beta$ (TGF- $\beta$ ), which is released in its active form through an external radio-frequency (RF) magnetic field $(58 \mathrm{mT}, 359 \mathrm{kHz})$ [17]. The heating favors the thermal degradation of the Sulfo-SMCC complex and frees the bioactive molecule [17]. Similarly, the group of Meikle et al. used thermoresponsive poly(epsilon-lysine) dendrons to tether Vascular Endothelial Growth Factor (VEGF) to magnetite MNPs [18]. Under the action of a 30 mT magnetic field, working at $293 \mathrm{kHz}$, this latter MDD 


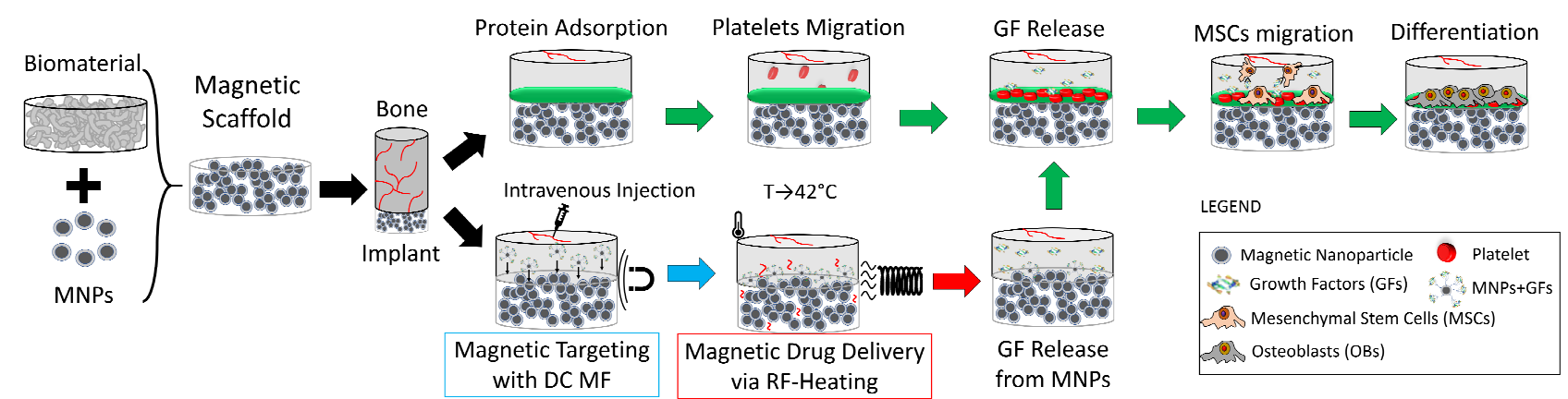

Fig. 1. Magnetic scaffolds (MagS) are biomaterial functionalized with magnetic nanoparticles (MNPs). They can be implanted to enhance bone healing. During normal healing, the proteins adsorb on the biomaterial, recalling the platelets, which release growth factors (GFs). The mesenchymal stem cells (MSCs) are attracted by GFs, then migrate, adhere to the MagS, proliferate and differentiate in osteoblasts (OBs). During this process, MNPs carrying GFs can be injected intravenously and attracted to the scaffold surface using a static magnetic field (DC MF). Then a radiofrequency (RF) field is applied to heat the system up to $42^{\circ} \mathrm{C}$ and release the GFs, which has the effect of fastening and enhancing the bone repair process.

system was heated from $20^{\circ} \mathrm{C}$ to $45^{\circ} \mathrm{C}$ in deionized water, for $300 \mathrm{~s}$. The $18 \%$ of $\ddagger$ loaded VEGF was released [18]. The choice of the GFs for the bio-conjugation is strategic for bone tissue engineering [2], [19]. VEGF is a biomolecule relevant for endochondral bone formation, since it recruits osteoprogenitor cells and has the ability of forming new blood vessels [19]. The TGF- $\beta$ stimulate bone formation by recruiting MSCs and increasing their proliferation, while affecting inflammation and angiogenesis [19]. However, the timing, dose and distribution affects VEGF and TGF-beta activity. Therefore, the therapeutic window should be carefully chosen to obtain high level of bone formation. Moreover, the amount of GF released must lie in the range 0.1-50 $\mu \mathrm{g} \cdot \mathrm{ml}^{-1}$, since higher concentrations can lead to tumor formation [3], [17].

Magnetic scaffolds were characterized in term of their morphological and functional properties [20]-[22], and were studied in a simplified way to investigate their potential in drug delivery applications [23], [24]. This work deals, for the first time, with the mathematical modeling of the combined use of magnetic scaffolds and MNPs carrying GFs to favor bone regeneration process. We aim to model the administration and drug transport of the MDD system to the MagS in a way controlled by an external static magnetic field, as presented in Fig. 1. The magnetic drug carriers are intravenously injected and attracted to the MNPs-loaded implant by using a static magnetic field. The drug is released after heating the system to $42^{\circ} \mathrm{C}$. The GF is then free to exert its specific biological action. The release of the GFs via RF-heating is investigated considering the multiphysics aspects involved in the process. Finally, the biological effect of the GFs is studied to evaluate if the proposed delivery strategy can favor the bone healing process and hence be of interest for regenerative medicine.

\section{THE MATHEMATICAL FRAMEWORK}

The case of a scaffold implanted in a long bone after surgery is considered. A transverse section of bone $\left(r_{b}=\right.$ $17.5 \mathrm{~mm}$, domain $\left.\Omega_{3}\right)$ with a $2 \mathrm{~mm}$ fracture gap $\left(r_{f}\right.$, domain

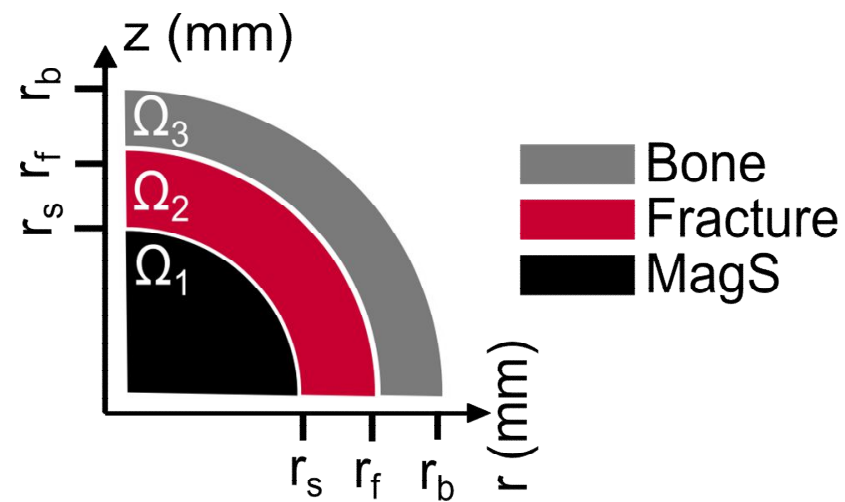

Fig. 2. 2D axial-symmetric analysis domain representing an implanted scaffold, in gray $\left(\mathrm{r}_{\mathrm{s}}=5.5 \mathrm{~mm}\right)$, surrounded by a fracture gap, depicted in red, $\left(r_{\mathrm{f}}=2 \mathrm{~mm}\right)$ and the host bone, shown in yellow $\left(\mathrm{r}_{\mathrm{b}}=10 \mathrm{~mm}\right)$.

TABLE I

PROPERTIES AND CHARACTERISTICS OF MAGNETIC SCAFFOLDS (MAGS)

\begin{tabular}{ccccc}
\hline \hline & $\begin{array}{c}\text { Impregnated } \\
\text { HA }\end{array}$ & MHA & FeHA-PCL & Unit \\
\hline $\mathrm{M}_{\mathrm{s}}$ & 414.45 & 310.8 & 336.7 & $\mathrm{kAm}^{-1}$ \\
$\mathrm{r}_{\mathrm{mnp}}$ & 50 & 10 & 14 & $\mathrm{~nm}$ \\
$\varphi$ & $12.5-25$ & 1.6 & 9.18 & $\%$ \\
Msat & $2.6-100.36$ & 0.94 & 6.15 & $\mathrm{kAm}^{-1}$ \\
\hline \hline
\end{tabular}

$\left.\Omega_{2}\right)$ and the scaffold $\left(r_{s}=5.5 \mathrm{~mm}\right.$, domain $\left.\Omega_{1}\right)$ is considered, as shown in Fig. 2. Assuming a spherical scaffold geometry or considering the cross-section of a cylindrical implant, the problem is reduced to a $2 \mathrm{D}$ axialsymmetric formulation in spherical coordinates.

\section{A. The Non-Linear Magnetostatic Problem}

In presence of a static magnetic flux density field $\left(\overline{R_{0}}\right)$, applied on the $z$-direction, the magnetic nanoparticles dispersed in the scaffold $\left(\Omega_{1}: 0<r<r_{s}\right)$ give rise to a uniform magnetization vector according to the following non-linear law [20], [25]:

$$
\bar{M}\left(\overline{B_{0}}, \varphi, T\right)=M_{s} \varphi L\left(\frac{\left|\overline{B_{0}}\right| \mu_{\mathrm{mnp}}}{k_{B} T}\right)
$$


where $k_{B}$ is the Boltzmann's constant, $T$ is the temperature of the system, $M_{s}$ is the saturation magnetization of the single nanoparticle in $\mathrm{Am}^{-1}$. The function $L(x)$ is the Langevin function [24]. The magnetic moment of the MNP is $\mu_{m n p}$, in $\mathrm{JT}^{-1}$ and $\varphi$ is the volumetric fraction of nanoparticles in the biomaterial matrix. For each scaffold the MNPs are assumed to be monodisperse in size and to be homogeneously distributed in the prosthetic implant [24], [26]. The MagS of interest are reported in Tab. I. We considered a ferrofluid impregnated hydroxyapatitecollagen scaffold (Impregnated HA) [20], an implant made of hydroxyapatite chemically doped with iron ions (MHA) [21] and a 3D printed poly-caprolactone (PCL) scaffold loaded with intrinsic magnetic hydroxyapatite (FeHA-PCL) [22]. Depending on MNPs characteristics and the manufacturing process, the saturation magnetization varies from low $\left(2.5 \mathrm{kAm}^{-1}\right)$ to very high values $\left(100 \mathrm{kAm}^{-1}\right)$ [20], [27]. It is very crucial to investigate how the material parameters can influence the proposed magnetically targeted drug delivery strategy sketched in Fig. 1.

In presence of the static external magnetic fields, strong field gradients arise between the scaffold and the surrounding diamagnetic tissues (creating a force field in the domain $\Omega_{2}$ and $\Omega_{3}$ ). Therefore, the magnetic carriers in the system will experience an attractive force toward the scaffold. Previous works which dealt with the numerical study of using magnetic scaffolds as a part of a magnetic drug delivery system solved the magnetostatic problem and inferred the possibility of attracting MNPs or magnetized cells by assuming that a magnetic field gradient higher than $1.3 \mathrm{Tm}^{-1}$ could be sufficient to determine a force capable of attracting MNPs to the scaffold [14], [16], [20], [23]. However, this is a limited view of the problem [24].

In this work, relying on a continuum-based approach, we refined the modeling of the magnetic attraction of MNPs to the scaffold by explicitly addressing the problem of the coupling between magnetostatic and mass transport phenomena. To this aim, the magnetic force exerted on the MNPs can be computed as [28]:

$$
\overline{F_{m}}=\frac{M_{s, \mathrm{mnp} 2} V_{\mathrm{mnp} 2}}{6 k_{B} T} \nabla|\bar{B}|^{2}
$$

where $M_{s, \text { пир } 2}$ is the saturation magnetization of the magnetic carrier to attract, whilst $V_{\text {mnp } 2}$ is the volume of the magnetic nanoparticle core. Fore the process sketched in Fig. 1, it is of pivotal interest to maximize Eq. (2). In this framework, from Eq. (2), we can already infer that it is possible to act of on the magnetic field gradient (i.e., on the strength of the external magnetic field or on the properties of the implanted magnetic scaffold). However, the magnetic drug delivery can be fostered by designing and manufacture magnetic carriers of growth factor with high saturation magnetization. However, recalling biocompatibility issues and hemodynamic problems, the volume of the MNPs to attract should be controlled [28]. From a material science point of view, the contemporary satisfaction of these criteria is a non-trivial task.

Under the action of the magnetic force in Eq. (2), the drug shuttles are set in motion with a velocity $v_{m}$ defined as [24], [28], [29]:

$$
\overline{v_{m}}=\frac{\overline{F_{m}}}{6 \eta r_{m-d}} \nabla|\bar{B}|^{2}
$$

where $r_{m-d}$ is the hydrodynamic radius of the MNPs plus the bioconjugated GF molecules and $\eta$ is the viscosity of the medium in $\mathrm{Pa} \cdot \mathrm{s}$. A value of $450 \mathrm{~Pa} \cdot \mathrm{s}$ was used to mimic the drag the MNPs would experience in the fibrin extracellular matrix [29]. The Comsol AC/DC module is used for solving the non-linear magnetostatic problem.

\section{B. Tissue-scale Modeling of Mass Transport and attraction of Magnetic Nanoparticles}

Given the knowledge of the magnetic field, force and the velocity, we face the coupling to the mass transport at the tissue-scale. The goal is to derive a framework which can predict the spatial distribution of the MNPs to attract.

The population of MNPs is subject to the magnetic force due to the scaffold presence and is drifted to the implant, against the action of a random dispersal flux [30]. To investigate the pattern of $\mathrm{C}_{\mathrm{mnp}}$ in the injured area, a diffusion-advection equation holds [24], [30], [31]:

$$
\frac{\partial C_{\mathrm{mnp}}}{\partial t}=D_{\mathrm{mnp}} \nabla^{2} C_{\mathrm{mnp}}-\overline{v_{m}} \nabla C_{\mathrm{mnp}}-k_{c} C_{\mathrm{mnp}}
$$

where $D_{m n p}$ is the diffusivity of the nanoscale drug delivery system, in $\mathrm{m}^{2} \mathrm{~s}^{-1}$. The influence of the scaffold on MNPs administration in the bone cavity is expressed by the term $v_{m}$ from Eq. (3). The degradation term $k_{c} C_{m n p}$ accounts for the capture and elimination of the nanoparticles from the endoplasmatic reticulum [32]. In this work, $k_{c}$ was set to $4.85 \cdot 10^{-7} \mathrm{~d}^{-1}$ for the size of the MNPs from Tab. II [32].

To solve Eq. (4), for simulate the magnetic drug delivery process from Fig. 1, it is necessary to constrain the concentration to a fixed value at the interface between bone and fracture (between domain $\Omega_{2}$ and $\Omega_{3}$ ). We assume here, differently from [23], [24], that the magnetic carriers are intravenously injected [30]. The concentration of MNPs at the host bone boundary is assumed to depend on particles characteristics and, for the first time, from the local, microvasculature tissue properties, so that [30], [31]:

$$
\left.C_{\text {mnp }}^{0}\right|_{\text {bone }}=C_{\text {mnp,inj }}^{0} \frac{L_{p} s(1-\theta)\left(P_{e}-P_{i}\right)}{e^{P e_{m v}-1}}
$$

where $C_{\mathrm{mnp} \text {,inj }}^{0} \mathrm{~s}$ the concentration of the injected MNPs in $\mathrm{mg} \cdot \mathrm{ml}^{-1}$. In Eq. (5), $\mathrm{L}_{\mathrm{p}}$ is the hydraulic conductivity of the vascular tissue, i.e. [31]: 
TABLE II

PARAMETERS FOR DESCRIBING THE INTRAVENOUS INJECTION OF MNPS

\begin{tabular}{ccc}
\hline Parameter Name & Value & Units \\
\hline$D_{\text {mnp,b }}$ & 25 & $\mathrm{~mm}^{2} \mathrm{~d}^{-1}$ \\
$\mathrm{~s}$ & 0.0018 & $\mathrm{~mm}^{-1}$ \\
$\mathrm{v}_{\mathrm{c}}$ & 0.1 & $\mathrm{~cm} \mathrm{~s}^{-1}$ \\
$1_{\mathrm{c}}$ & 25 & $\mu \mathrm{m}$ \\
$\psi$ & 0.001 & Adim. \\
$\mathrm{r}_{\mathrm{c}}$ & 0.1 & $\mu \mathrm{m}$ \\
$\eta_{\mathrm{b}}$ & 3 & $\mathrm{cP}$ \\
$\mathrm{t}_{\mathrm{m}}$ & 0.5 & $\mu \mathrm{m}$ \\
\hline
\end{tabular}

$$
L_{p}=\frac{\psi r_{c}^{2}}{8 \eta_{b} t_{m} \sqrt{\psi}}
$$

where $\psi$ is the porosity of the capillaries, whilst $r_{c}$ is the average radius of the capillaries $\mu \mathrm{m}, \eta_{\mathrm{b}}$ is the blood viscosity, and $t_{m}$ is the thickness of capillary membranes in $\mu \mathrm{m}$, which are reported in Tab. II [31]. The symbol $s$ is the surface area of capillaries per volumetric unit of tissue, as reported in Tab. II.

In Eq. (5) $\theta$ indicates the sieving coefficient, which depends on the ratio between the size of the carrier $\left(v=r_{m n p} / r_{C}\right)$ and the pore of:

$$
\theta=(1-v)^{2}\left[2-(1-v)^{2}\right]\left[1-\frac{2}{3} v^{2}-0.136 v^{3}\right]
$$

The sieving (i.e., 1- $\theta$ ) is almost total (i.e., around 99\%) for both the MNPs [17], [18], considered in this work.

The terms $\mathrm{P}_{\mathrm{e}}$ and $\mathrm{P}_{\mathrm{i}}$ are the Sterling's and interstitial pressure, $25 \mathrm{mmHg}$ and $-3 \mathrm{mmHg}$ respectively, and $\mathrm{Pe}_{\mathrm{mv}}$ is the Peclet number of the micro-vascular system [31]:

$$
P_{m v}=\frac{v_{c} l_{c}}{D_{m n p, b}}
$$

where $1_{c}$ is the average capillary length in $\mu \mathrm{m}$. These parameters are related to the microvasculature and blood flow properties. It should be noticed that the diffusion coefficient of MNPs in blood $\left(D_{m n p, b}\right)$ is calculated considering blood viscosity, and it is therefore different from the value the magnetic carriers experiences in the extracellular matrix, during the attraction to the magnetic scaffold. Given this difference, The Peclet number magnitude is relatively high, since the average velocity of blood in capillaries is moderate but the nanoparticles are very small-sized object and are subject to high drift in the blood vessels. This causes the velocity of filtration in Eq. (4), i.e., $L_{p}\left(P_{\varepsilon}-P_{\ell}\right)$, to be equal to circa $0.4-0.5 \mathrm{mms}^{-1}$.
To respect symmetry, two Neumann-line zero-flux boundary conditions were applied to the $\mathrm{r}$ - and $\mathrm{z}$-axes. TABLE III

FEATURES OF THE MAGNETIC DRUG CARRIERS

\begin{tabular}{cccc}
\hline \hline & VEGF+MNPs [18] & $\begin{array}{c}\text { TGF- } \beta+\text { MNPs } \\
{[17]}\end{array}$ & Unit \\
\hline$M_{s, m n p 2}$ & 60.0 & 80.0 & ${\mathrm{emu} \cdot \mathrm{g}^{-1}}$ \\
$V_{\text {mnp } 2}$ & 53.0 & 4188.8 & $\mathrm{~nm}{ }^{3}$ \\
$r_{m-d}$ & 16.7 & 53.0 & $\mathrm{~nm}$ \\
$D_{m n p}$ & 0.1 & 0.3 & $\mathrm{~mm}^{2} \mathrm{~d}^{-1}$ \\
$k_{r e l}$ & 0.8 & 12.0 & $\mathrm{~h}^{-1}$ \\
$C_{\text {mnp,inj }}^{0}$ & 40.0 & 6.7 & $\mathrm{mg} \cdot \mathrm{ml}^{-1}$ \\
$C_{G F}^{0}$ & & & \\
$B_{0}$ & 19 & 40.0 & $\mu \mathrm{g} \cdot \mathrm{ml}^{-1}$ \\
$f$ & 30 & 58 & $\mathrm{mT}$ \\
SAR & 293 & 350 & $\mathrm{kHz}$ \\
\hline \hline
\end{tabular}

Typically, in the literature, the works which cope with the mathematical modeling of MNPs attraction and biodistribution neglect this contribution to the final solution [24], [28], [30]. This approach could be of interest for other tissues and magnetic drug delivery systems.

To solve Eq. (4), the concentration of MNPs is assumed to be zero at the initial time, whilst zero flux boundary condition is considered at the scaffold surface (see Fig. 2).

The attraction of the nano-carriers from Tab. III [17], [18], is assessed for the three scaffolds from Tab. I under different magnetic field strengths. From this analysis, the most effective MagS is selected. The Transport of Dilute Species interface from Comsol is used to solve the mass transport problem [Eq.s (4)-(8) using the solution of Eq. (2)].

\section{Drug Release via RF-Heating}

As described in Sect. I and showed in Fig. 1, after the injection and the following attraction of the magnetic carriers to the scaffold, the static magnetic field is turned off and a time-varying magnetic field is applied [6], [17], [18] to heat the magnetic carriers and reach an average macroscopic temperature of $42^{\circ} \mathrm{C}$, to destroy the linkers and freeing the biomolecules [18]. We assume that the release temperature does not alter the GFs activity. Furthermore, the time required to reach $42^{\circ} \mathrm{C}$ is considered so low that the biological system is not damaged.

The RF-heating was carefully modeled solving the Pennes' bioheat equation in the analysis domain $\left(\Omega_{1} \Omega_{3}\right)$ of Fig. 2 [26], [33]:

$$
\rho C_{p} \frac{\partial T}{\partial t}=k \nabla^{2} T-\rho_{b} C_{p, b} \omega_{b} \Delta T+Q+Q_{M}
$$

where $\rho$ is tissue density in $\mathrm{kg} \cdot \mathrm{m}^{-3}, C_{p}$ is the specific heat in $\mathrm{Jkg}^{-1} \mathrm{~K}^{-1}$. The terms $\rho_{b}, C_{p, b}$ indicates the thermal blood properties, with $\omega_{b}$ being the tissue perfusion and $Q_{M}$ the metabolic heat. 
TABLE IV

THERMAL PROPERTIES OF MAGNETIC SCAFFOLDS AND TISSUES AT $37^{\circ} \mathrm{C}$

\begin{tabular}{lcccc}
\hline \hline & $\begin{array}{c}\mathbf{k} \\
\left(\mathbf{W ~ m}^{-1} \mathbf{K}^{-\mathbf{1}}\right)\end{array}$ & $\begin{array}{c}\mathbf{C}_{\mathbf{p}} \\
\left(\mathbf{J ~ k g}^{-1} \mathbf{K}^{-\mathbf{1}}\right)\end{array}$ & $\begin{array}{c}\mathbf{Q}_{\mathbf{M}} \\
\left(\mathbf{W m}^{-\mathbf{3}}\right)\end{array}$ & $\begin{array}{c}\mathbf{\omega}_{\mathbf{B}} \\
\left(\mathbf{s}^{-1}\right)\end{array}$ \\
\hline $\mathbf{H a}$ & 1.3 & 700 & $/$ & $/$ \\
$\mathbf{P C L}$ & 1.75 & 1300 & $/$ & $/$ \\
$\begin{array}{l}\text { Fracture } \\
\text { (inflamed) }\end{array}$ & 0.558 & 2450 & 5262.5 & $6.95 \mathrm{e}-3$ \\
$\begin{array}{l}\text { Fracture } \\
\text { (ischemic) } \\
\text { Bone }\end{array}$ & 0.1 & 2450 & 342.1 & $0.262 \mathrm{e}-3$ \\
\hline \hline
\end{tabular}

TABLE V

ELECTROMAGNETIC PROPERTIES OF MAGNETIC SCAFFOLDS AND TISSUES AT $37^{\circ} \mathrm{C}$

\begin{tabular}{lcccc}
\hline \hline & $\begin{array}{c}\boldsymbol{\varepsilon} \\
(\mathbf{2 9 3} \mathbf{~ k H z})\end{array}$ & $\begin{array}{c}\boldsymbol{\sigma} \\
(\mathbf{2 9 3} \mathbf{~ k H z}) \\
\mathbf{S m}^{-\mathbf{1}}\end{array}$ & $\begin{array}{c}\boldsymbol{\varepsilon} \\
\mathbf{3 5 0} \mathbf{~ k H z})\end{array}$ & $\begin{array}{c}\boldsymbol{\sigma} \\
\mathbf{( 3 5 0} \mathbf{~ k H z}) \\
\mathbf{S m}^{-\mathbf{- 1}}\end{array}$ \\
\hline Ha & 12.5 & $2.1 \cdot 10^{-3}$ & 12.01 & $2.3 \cdot 10^{-3}$ \\
PCL & 2.2 & $10^{-5}$ & 2.17 & $0.68 \cdot 10^{-4}$ \\
Fracture & 3580 & 0.545 & 3420 & 0.551 \\
$\begin{array}{l}\text { (inflamed) } \\
\text { Fracture } \\
\text { (ischemic) }\end{array}$ & 1321.5 & 0.196 & 1293.25 & 0.199 \\
Bone & 192 & 0.0214 & 187.2 & $2.14 \mathrm{e}-2$ \\
\hline \hline
\end{tabular}

In this framework, the problem is assumed in this work to be non-linear and multiphysics. During the RF-heating, the system temperature increases and the electric, magnetic and thermal properties of the materials and tissues modifies, thus changing the dissipated power and the heat transfer during the exposure. These aspects must be taken into account for properly studying the magnetic drug delivery process shown in Fig. 1.

The electromagnetic problem is solved in the frequency domain for the geometry of Fig. 2 by employing the Comsol RF module. A uniform and homogeneous distribution is considered as background field. The spatial distribution of the magnetic field is computed considering the magnetic scaffold in Tab. I.

The electromagnetic problem is bi-directionally coupled to the bioheat transfer problem, which is solved in the time domain using the Bioheat Transfer module from Comsol.

As explained in [33], the resolution is carried out considering that the electromagnetic and thermal field have very different time scales, thus considering the calculation of electric and magnetic field as a stationary problem, Then, starting from the initial temperature distribution at time $\mathrm{t}=$ 0 , the power losses can be evaluated and used to solve Eq. (9). Given the new temperature distribution at time $t+\Delta t$, the Maxwell's equations and the deposited power can be computed again to re-evaluate Eq. (9). This scheme implemented using a frequency-transient solver [33].

The thermal properties are assumed to linearly increase with a $1{ }^{\circ} \mathrm{C}$ increase of $0.5 \%$ for the thermal conductivities, whilst a $1{ }^{\circ} \mathrm{C}$ increase of $0.33 \%$ is assumed for the specific heat [33]. The heat capacity of blood has been assumed linear with a $1 \% \cdot{ }^{\circ} \mathrm{C}^{-1}$ in the temperature range from $37^{\circ} \mathrm{C}$ to $70^{\circ} \mathrm{C}$. The blood tissue perfusion $\left(\omega_{b}\right)$ is a non-linear function of temperature [33].
Differently from the interstitial hyperthermia treatment of bone tumors [26], [33], the exposure time is not of tens of minutes, but of the order of few to tens of seconds, because the threshold temperature of $42^{\circ} \mathrm{C}$ must be reached in the proximity of the implant and three different heat sources are present. The total electromagnetic power per unit volume deposited during the heating is:

$$
Q=Q_{s c}+Q_{m n p}+Q_{t}
$$

The heat dissipated by the magnetic scaffolds is [33]:

$$
Q_{s c}=\pi f|H|^{2} \chi^{\prime \prime}(T)
$$

where $f$ is the working frequency, in $\mathrm{Hz}, H$ is the magnetic field vector in $\mathrm{Am}^{-1}$ and $\chi^{\prime \prime}(T) \mathrm{s}$ the imaginary susceptibility of the magnetic scaffolds. In Eq. (11), we explicitly consider the temperature dependence in the ColeCole susceptibility spectra of magnetic scaffolds [33]. which is a non-linear function of temperature, as described in [26], [33]. The heat dissipated by the biological tissues is:

$$
Q_{t}=\frac{1}{2}|E|^{2} \sigma
$$

where $\sigma$ is the electrical conductivity of biological tissues, in $\mathrm{Sm}^{-1}$, and $E$ is the induced electric field, in $\mathrm{Vm}^{-1}$. The dielectric properties, reported in Table $\mathrm{V}$ at $37^{\circ} \mathrm{C}$, are assumed to linearly increase with temperature, with a variation of $3 \%{ }^{\circ} \mathrm{C}^{-1}[33]$. The scaffolds and tissues thermal and electromagnetic properties are taken from [24], [26], [33] and reported in Tab. IV and V.

The heat dissipated by the concentration of injected MNPs is evaluated as $Q_{m n p}=S A R \cdot C_{m n p}$ [34]. The MNPs distribution is recovered from the solution of Eq. (4), implying that $Q_{m n p}(r, z, t)$, i.e. it is a function of position and time. The Specific Absorption Rate (SAR) of the MNPs reported in Tab. II was retrieved by the initial slope method [34] from the experimental data of [17], [18].

Eq. (9) is solved assuming open boundary at the outer bone interface $\left(\Omega_{3}\right)$ and imposing an initial temperature of $37^{\circ} \mathrm{C}$ for all tissues. The thermal insulation condition is applied for symmetry along the $\mathrm{r}$ - and $\mathrm{z}$-axis.

\section{Bone RePair Process: Physiology AND MATHEMATICAL MODELING}

\section{A. Physiological Process \& Biomathematics}

The aim of this work is the modeling and investigation of how magnetic scaffold, after their implantation, could be used as the core of a magnetically targeted drug delivery system for magnetic nanoparticles functionalized with biomolecules. To this aim, it is crucial to include the bone healing process, summarized in Fig. 1, in our model [35][45]. Then, this model must be modified to account for the drug delivery guided by magnetic attraction and triggered 
by RF-heating (see Fig. 1).

In this work, the bone healing process (Fig. 1) is described using the model work of Moreo et al. [36], [37]. This model was already analyzed in the literature in terms of sensitivity, stability, existence of the solution and the apriori error estimate [36]-[38]. Therefore, the set of nine non-linear reaction-diffusion coupled equations developed to account for the early stages of bone healing is slightly modified and used for simulating the physiological process shown in Fig. 1. Considering a moderate mechanical stimulation, a continuum-based approach is used to describe the spatio-temporal dynamics of the biological elements depicted in Fig. 1.

In presence of a biomaterial, the bone healing process initiates with a surgical or accidental fracture and with blood vessel injury [36], [39]. The bone cavity is immediately filled with blood [35]. Plasma, platelets and proteins invade the injured area. As depicted in Fig. 1 in the manuscript, firstly proteins (e.g., plasmin, albumin) adsorb onto biomaterial surface (within $\mu \mathrm{s}$ ) [40], [41]. Therefore proteins $\left(\mathrm{p}, \mu \mathrm{g} \cdot \mathrm{mm}^{-2}\right)$ adhesion onto the rough biomaterial surface $\left(\mathrm{p}_{0}=0.5 \mu \mathrm{g} \cdot \mathrm{mm}^{-2}\right)$ is assumed to be a steady-state process [20], [36]:

$$
D_{p} \nabla^{2} p-\gamma_{p} p=0
$$

where $D_{p}$ is protein diffusion coefficient and $\gamma_{p}$ is the linear decay rate. The value of both $D_{p}$ and $\gamma_{p}$ are chosen to get a characteristic diffusion length $\left(l_{\text {diff }}=\sqrt{D_{p} / \gamma_{p}}\right)$ of about 0.1

mm. Subsequently the coagulation process begins with platelets (c, cells $\cdot \mathrm{ml}^{-1}$ ) activation, migration to the biomaterial and the following release of several GFs, such as VEGF or TGF- $\beta$ [19]. The platelets dynamic obeys the following random dispersal motion and taxis [36]:

$$
\frac{\partial c}{\partial t}=\nabla \cdot\left[D_{c} \nabla c-H_{c} \nabla p\right]-A_{c} c
$$

where $H_{c}$ is a chemotaxis coefficient and $A_{c}$ is a linear decay rate.

As platelets start diffusing and moving down protein chemotactic gradient, they release an angiogenic GFs, whose concentration is $s_{1}(r, z, t)$ (Fig. 1). This molecule is able to recruit osteo-progenitor cells, exactly as VEGF or TGF- $\beta$ [17]-[19]. Since the proposed magnetic drug delivery strategy, shown in Fig. 1, aims to introduce more growth factors and boost the cellular response it is of great relevance to model the dynamics of the growth factor $s_{1}$. In physiological conditions (without drug delivery), the mass balance equation for the biomolecule $s_{1}$ is [36]:

$$
\begin{aligned}
& \frac{\partial s_{1}}{\partial t}=\nabla \cdot\left[D_{\mathrm{s} 1} \nabla s_{1}\right]+ \\
& +\left(\frac{\alpha_{c 1} p}{\beta_{c 1}+p}+\frac{\alpha_{c 2} s_{1}}{\beta_{c 2}+s_{1}}\right) c-A_{s 1} s_{1}
\end{aligned}
$$

where the kinetic terms in parentheses represent GFs secretion by platelets $(p)$ and model their degree of activation. The linear decay rate, $\mathrm{A}_{\mathrm{s} 1}$, accounts for the low bio-availability of GFs in vivo [36].

During the release of the angiogenic growth factor by platelets, the fibrin network assemblies in an ischemic environment [42]. Then hematoma forms, locally necrosis takes place and the inflammatory phase establishes [35]. Around 2-10 days, while MSCs migrate from the host bone following the chemotactic gradient of GFs, the angiogenesis process starts to build new vessels [19]. At about 14 days, the osteoprogenitor cells differentiate in Osteoblasts (OBs) and initiate to deposit the mineral bone matrix [39]. The main biological actors of bone healing, MSCs, migrate from the host bone towards biomaterial surface along gradients of both the angiogenic, i.e., $\mathrm{s}_{1}$, and the osteogenic GFs, i.e., $\mathrm{s}_{2}$. The influence of the GF $\mathrm{s}_{1}$ is twofold, since it also favors the differentiation of MSCs into the osteoblastic phenotype. In mathematical terms the patterns of osteogenic cells, $m(r$, $z, t$ ), can be obtained by the following equation [36]:

$$
\begin{aligned}
& \frac{\partial m}{\partial t}=\nabla \cdot\left[D_{\mathrm{m}} \nabla m-m\left(B_{m 1} \nabla s_{1}+B_{m 2} \nabla s_{2}\right)\right]+ \\
& +\left(\alpha_{m 0}+\frac{\alpha_{m} s_{1}}{\beta_{m}+s_{1}}+\frac{\alpha_{m} s_{2}}{\beta_{m}+s_{2}}\right) m\left(1-\frac{m}{N}\right)+ \\
& -\left(\frac{\alpha_{m b} s_{1}}{\beta_{m b}+s_{1}}+A_{m}\right) m
\end{aligned}
$$

where the parameters are listed and explained in Tab. VI [36]. With respect to the model of Moreo et al. [36], the taxis coefficients $B_{m 1}, B_{m 2}$ are assumed herein to be not constant, but limited to a maximum velocity value [43], [44], i.e.:

$$
\begin{aligned}
& B_{m 1}=\frac{\sigma_{1} B_{m 10}}{1+\eta_{1} s_{1}} \\
& B_{m 2}=\frac{\sigma_{2} B_{m 20}}{1+\eta_{2} s_{2}}
\end{aligned}
$$

where $\sigma_{1}$ is $0.05, \eta_{1}$ is $0.033 \mathrm{ml} \mathrm{ng}^{-1}, \sigma_{2}$ and $\eta_{2}$ are 0.01 and $0.050 \mathrm{ml} \cdot \mathrm{ng}^{-1}$, respectively. In this way, the chemotaxis coefficients are written in the form of a density-dependent sensitivity model and an upper bound for the chemotaxis velocity exists when the concentration of the chemical agent is elevated [43], [44]. This modification allows to avoid the blow-up of the solutions, while maintaining a meaningful and physical representation of cells concentration in the analysis domain.

As regards the osteogenic growth factor $s_{2}$ (e.g., BMP) the analytical balance is the following [36]: 


$$
\begin{aligned}
& \frac{\partial s_{2}}{\partial t}=\nabla \cdot\left[D_{s 2} \nabla s_{2}\right]+ \\
& \left(\frac{\alpha_{m 2} s_{2}}{\beta_{m 2}+s_{2}} m+\frac{\alpha_{b 2} s_{2}}{\beta_{b 2}+s_{2}} b\right)-A_{s_{2}} s_{2}
\end{aligned}
$$

The availability of both growth factors causes the MSCs to differentiate into osteoblasts, which then produce the new bone in the fracture gap [36]. The dynamics of osteoblasts obeys the following equation [36]:

$$
\frac{\partial b}{\partial t}=\frac{\alpha_{m b} s_{1}}{\beta_{m b}+s_{1}}-A_{b} b
$$

After the differentiation, the creation of new and nonmature bone starts with the degradation of the temporary extracellular fibrin assembly produced by the platelets (Fig. $1)$. Therefore, the fraction of fibrin matrix $\left(v_{f}\right)$ can be investigated by solving the following equation [36]:

$$
\frac{\partial v_{f}}{\partial t}=-\frac{\alpha_{w} s_{2}}{\beta_{w}+s_{2}} b v_{f}\left(1-v_{w}\right)
$$

Then the periostium can undergo bone formation and intramembraneous ossifications, which determine woven bone production and the callus presence [35], [39]-[42]. In mathematical terms:

$$
\frac{\partial v_{w}}{\partial t}=\frac{\alpha_{w} s_{2}}{\beta_{w}+s_{2}} b v_{f}\left(1-v_{w}\right)-\gamma v_{w}\left(1-v_{l}\right)
$$

Finally, bone remodelling process works to form the mature lamellar bone [39], [45], whose spatial and temporal distribution can be computed by solving [36]:

$$
\frac{\partial v_{l}}{\partial t}=\gamma v_{w}\left(1-v_{l}\right)
$$

Essentially, to summarize, the implant of the MagS initiates a cascade of biological events: protein adsorption [35], [40], [41], which determines platelets migration [36], [39], leading to the release of osteogenic (e.g., BMP-2) and angiogenic growth factors (i.e., VEGF or TGF- $\beta$ ) [19]. As a result, the stem cells are recruited by the growth factors signaling, then migrate to the scaffold, where they proliferate and differentiate into osteoblast, which, finally, secrete the bone matrix.

With the model (Eq. (13)-(22), solved on $\Omega_{2}$ in Fig. 2) is possible to evaluate the distribution of osteoblasts and then the production of lamellar bone $\left(v_{l}\right)$. The external and additional contribution of the MDD acts directly on Eq. (15) and indirectly on osteoblasts.

Zero flux condition applies to all boundaries (host bone, implant surface and symmetry axes in Fig. 3 in the manuscript) for $\mathrm{p}, \mathrm{c}, \mathrm{s}_{1}, \mathrm{~s}_{2}, \mathrm{~m}, \mathrm{~b}, \mathrm{v}_{\mathrm{f}}, \mathrm{v}_{\mathrm{w}}, \mathrm{v}_{1}$.

A time-dependent Dirichlet boundary condition applies for the osteogenic cells at the host bone surface [36]. In fact, as derived from physiology, the cell density value is set to $2 \cdot 10^{5}$ cells $\cdot \mathrm{ml}^{-1}$ for the first 14 days. This nonlinearity is implemented defining a step function continuous in its second derivative and applying it to host bone boundary.

As regards the initial conditions, the platelets are assumed to have an initial concentration of $2.5 \cdot 10^{8}$ cells $\mathrm{ml}^{-1}$, whereas $m$ and $b$ have a starting concentration of $10^{3}$ cells $\cdot \mathrm{ml}^{-1}$. Regarding the growth factors, both $\mathrm{s}_{1}$ and $\mathrm{s}_{2}$ are assumed to be poorly concentrated at time $\mathrm{t}=0$, hence their initial value is set to $1 \mathrm{ng} \cdot \mathrm{ml}^{-1}$ [36].

The bone healing process shown in Fig. 1 was simulated for a period of 365 days, with a 1 day step, in presence of the magnetic scaffolds and in absence of external field and drug stimulation. The Comsol Mathematics interface is used. Since the several model variables have a strong mutual interdependence, it is worth to explain the relationship between the aforementioned physical quantities. The protein mass balance is first solved. Then, the spatial distribution of $p$ is employed to evaluate the platelets dynamic, while solving for the growth factors $s_{1}$ and $s_{2}$, together with the MSCs $(m)$ and the osteoblasts $(b)$. Then, in sequence, $v_{f}$ is computed, then $v_{w}$ and, finally $v_{l}$.

\section{B. Bone Healing Outcomes}

Currently available MagS demonstrated the capability to increase MSCs adhesion, proliferation and differentiation thanks to a rough surface microtopography [46], [47]. The bone integration was experimentally observed in absence of drug delivery. However, we hypothesize that the bonehealing process can be further enhanced with magnetically targeted drug delivery of MNPs carriers of GFs [6]-[9], [15]-[18].

TABLE VI

PARAMETERS FOR THE BONE HEALING SIMULATIONS

\begin{tabular}{cccc}
\hline Parameter & VEGF & TGF- $\beta$ & Unit \\
\hline $\mathrm{p}_{0}$ & 0.5 & 0.5 & $\mu \mathrm{g} \mathrm{mm}^{-2}$ \\
$\mathrm{D}_{p}$ & 0.001 & 0.001 & $\mathrm{~mm}^{2}$ day $^{-1}$ \\
$\gamma_{p}$ & 0.01 & 0.01 & day $^{-1}$ \\
$\mathrm{D}_{c}$ & 1.365 & 1.365 & $\mathrm{~mm}^{2}$ day $^{-1}$ \\
& $10^{-2}$ & $10^{-2}$ & \\
$\mathrm{~A}_{c}$ & 0.067 & 0.067 & day $^{-1}$ \\
$\mathrm{H}_{c}$ & 0.333 & 0.333 & $\mathrm{~mm}^{4}(\text { day } \mu \mathrm{g})^{-1}$ \\
$\mathrm{D}_{m}$ & 0.133 & 0.133 & $\mathrm{~mm}^{2}$ day $^{-1}$ \\
$\mathrm{~B}_{m 10}$ & 0.2 & 0.667 & $\mathrm{~mm}^{2}$ day $^{-1}(\mathrm{ng} / \mathrm{ml})^{-1}$ \\
$\mathrm{~B}_{m 20}$ & 0.167 & 0.167 & $\mathrm{~mm}^{2}$ day $^{-1}(\mathrm{ng} / \mathrm{ml})^{-1}$ \\
$\alpha m 0, \alpha m$ & 0.25 & 0.25 & day $^{-1}$ \\
$\mathrm{~N}$ & $10^{6}$ & $10^{6}$ & cells $\mathrm{ml}^{-1}$ \\
$\mathrm{~A}_{m}$ & $210^{-3}$ & $210^{-3}$ & day $^{-1}$
\end{tabular}




\begin{tabular}{|c|c|c|c|}
\hline$\alpha m b$ & 0.5 & 0.5 & day $^{-1}$ \\
\hline$\beta_{m}, \beta_{m b}$ & 10 & 10 & $\mathrm{ng} \mathrm{ml} \mathrm{l}^{-1}$ \\
\hline $\mathrm{A}_{b}$ & $6.6710^{-3}$ & $6.6710^{-3}$ & day $^{-1}$ \\
\hline $\mathrm{D}_{s} 1$ & 0.3 & 0.85 & $\mathrm{~mm}^{2}$ day $^{-1}$ \\
\hline $\mathrm{D}_{s} 2$ & 0.1 & 0.1 & $\mathrm{~mm}^{2}$ day $^{-1}$ \\
\hline $\mathrm{A} s 1, \mathrm{~A} s 2$ & 10 & 10 & day $^{-1}$ \\
\hline$\alpha_{c 1}$ & $6.6710^{-5}$ & $\begin{array}{c}6.67 \\
10^{-5}\end{array}$ & $\mathrm{ng} \mathrm{ml}^{-1}$ day $^{-1}(\text { cells } / \mathrm{ml})^{-1}$ \\
\hline$\alpha_{c 2}$ & $10^{-5}$ & $10^{-5}$ & $\mathrm{ng} \mathrm{ml}^{-1}$ day $^{-1}(\text { cells } / \mathrm{ml})^{-1}$ \\
\hline$\alpha_{m 2}$ & $6.6710^{-5}$ & $6.6710^{-5}$ & $\mathrm{ng} \mathrm{ml}^{-1}$ day $^{-1}(\text { cells } / \mathrm{ml})^{-1}$ \\
\hline$\alpha b 2$ & $2.510^{-5}$ & $2.510^{-5}$ & $\mathrm{ng} \mathrm{ml}^{-1}$ day $^{-1}(\text { cells } / \mathrm{ml})^{-1}$ \\
\hline$\beta_{c 1}$ & 0.1 & 0.1 & $\mu \mathrm{g} \mathrm{mm}^{2}$ \\
\hline$\beta_{c 2}, \beta_{m 2}, \beta_{b 2}$ & 10 & 10 & $\mathrm{ng} \mathrm{ml^{-1 }}$ \\
\hline$\alpha_{w}$ & $10^{-7}$ & $10^{-7}$ & day $^{-1}(\text { cells } / \mathrm{ml})^{-1}$ \\
\hline$\beta_{w}$ & 10 & 10 & $\mathrm{ng} \mathrm{ml^{-1 }}$ \\
\hline$\gamma$ & 20 & 20 & a.u. \\
\hline
\end{tabular}

Therefore, we consider the physiological osteogenesis in presence of a biomaterial as the reference situation. We aim to evaluate, for the first time, if the combination of MagS and magnetic drug delivery can alter and favor the osteogenesis. To this aim, under physiological conditions, the homogeneity $(\xi)$ of the lamellar bone fraction $\left(v_{l}\right)$ in the fracture gap is considered as biological outcome. This quantity is evaluated as the ratio of the mean value of $v_{l}$ to its standard deviation. In mathematical terms:

$$
\xi=\frac{v_{l, \text { mean }}}{v_{l, \text { std }}}
$$

If the mean value of the mature bone fraction is high and its standard deviation is low, the resulting bone is of high quality and the damage can be considered as repaired [39], [35]. The homogeneity of bone determines the mechanical properties. Hence, the Young modulus (E, in GPa) of new bone is evaluated as a function of lamellar bone [48]:

$$
\begin{aligned}
& E\left(v_{l}\right)=8.83 \cdot 10^{5}\left(1-v_{l}\right)^{6}+ \\
& -2.99 \cdot 10^{6}\left(1-v_{l}\right)^{5}+3.99 \cdot 10^{6}\left(1-v_{l}\right)^{4}+ \\
& -2.64 \cdot 10^{6}\left(1-v_{l}\right)^{3}+9.08 \cdot 10^{5}\left(1-v_{l}\right)^{2}+ \\
& -1.68 \cdot 10^{5}\left(1-v_{l}\right)+2.37 \cdot 10^{4}
\end{aligned}
$$

\section{Effects of Magnetic Drug Delivery}

In the case of VEGF or TGF- $\beta$ release from the MNPs attracted to the scaffold site, MSCs distribution and their

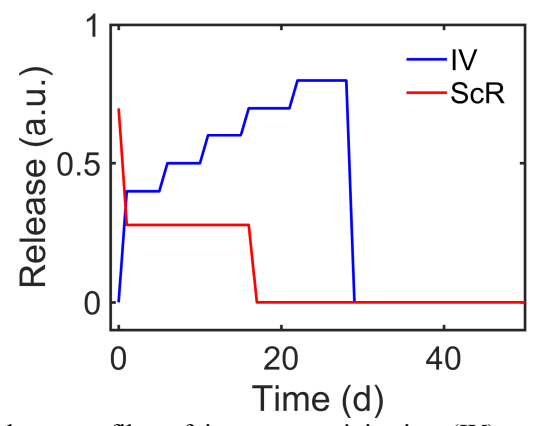

Fig. 3. Release profiles of intravenous injection (IV) and release from scaffold (ScR) of growth factors (GFs). The IV profile is taken from [49]. The ScR profile is derived from the experimental data from [55]-[57].

differentiation rate into a higher OBs augments due to an increase in $\mathrm{s}_{1}$ concentration. To model the further availability of $s_{1}$ due to the RF-heating release, the following generation term $R_{m, s l}$ is added to the r.h.s. of Eq. (15):

$$
R_{m, s 1}=k_{\text {rel }} \frac{C_{G F}^{0}}{C_{\text {mnp,inj }}^{0}} C_{\text {mnp }} e^{\frac{T-T_{t h}}{2 v^{2}}} \Pi\left(t / T_{d}\right)
$$

where $\mathbb{I l}(t)$ is a rectangular unit window of duration $T_{d}$. This function permits to simulate the injection of the MDD system and the GFs release for any given time of the healing process $(1 \mathrm{~d}, 14 \mathrm{~d}, 28 \mathrm{~d}, 60 \mathrm{~d}) . T_{d}$ is 1 day and $C_{G F}^{0}$ $\left(\mu \mathrm{g} \cdot \mathrm{ml}^{-1}\right)$ is the dose of growth factor linked to the MNPs surface. This quantity is assumed to be a constant for each carrier, e.g., $0.194 \mu \mathrm{g}$ of VEGF for mg of nanoparticle [18], as reported in Tab. II. The MNPs concentration, $C_{m n p}$, is the solution of Eq. (4) at the final time. As explained in Sect. I, the GFs are bound to the MNPs using proteic or aminoacidic linkers which degrade if heated at the threshold temperature $T_{\text {th }}=42^{\circ} \mathrm{C}$ for several minutes [17], [18]. The term $v$ is equal to $0.3^{\circ} \mathrm{C}$, to account for the narrow release temperature range observed experimentally [17], [18].

\section{Comparison with Traditional Drug Delivery} Strategies

The combined use of MagS and MDD is numerically validated against the traditional and established drug delivery methodologies of GFs direct injection [3], [49].

The direct injection of VEGF or TGF- $\beta$ is simulated by adding the following time-dependent Dirichlet boundary condition for solving Eq. (15) for $s_{1}$ on the boundary between domains $\Omega_{2}$ and $\Omega_{3}$ [30], [50]-[52]:

$$
\begin{aligned}
& R_{i n j}=C_{G F}^{0} \frac{L_{p} s(1-\theta)\left(P_{e}-P_{i}\right)}{e^{P e_{m v}}-1} F_{1}(t) \\
& F_{1}(t)= \begin{cases}0 & 0<\mathrm{t}<1 \\
0.4 & 1<\mathrm{t}<5 \\
0.5 & 5<\mathrm{t}<10 \\
0.6 & 10<\mathrm{t}<15 \\
0.7 & 15<\mathrm{t}<20 \\
0.8 & 20<\mathrm{t}<28 \\
0 & \mathrm{t}>28\end{cases}
\end{aligned}
$$


The spatio-temporal release $\left(F_{1}(t)-\mathrm{IV}\right)$ is assumed equal to the experimental results from [53], [54], as shown in Fig. 3. It should be noted that the release is quite high after 1 day (i.e., about the $40 \%$ of the loaded GF) and then is maximum after 28 days, implying that the release is incomplete. The microvascular parameters for the first of Eq. (26) are evaluated for the VEGF or the TGF- $\beta$.

Furthermore, the GFs release from the scaffold was simulated. A drug-loaded implant with similar chemical and physical features was retrieved in the literature [55]. A time-dependent $\mathrm{BC}$ for $\mathrm{s}_{1}$ is imposed on the scaffold boundary to simulate the concentration profiles of [56], [57]:

$$
\begin{aligned}
& R_{s c}=C_{G F}^{0} e^{-\frac{\sqrt{r^{2}+z^{2}}}{\kappa}} F_{2}(t) \\
& F_{2}(t)= \begin{cases}0.7 & 0<\mathrm{t}<1 \\
0.28 & 1<\mathrm{t}<16 \\
0 & 16<\mathrm{t}<365\end{cases}
\end{aligned}
$$

The concentration of GFs released from the scaffold is assumed to exponentially decrease with the distance, being ineffective after distance $\kappa=0.1 \mathrm{~mm}$, and with the cumulative release trend from [55]-[57], which is shown in Fig. 3.

The homogeneity of lamellar bone density for the cases of the novel MDD are compared to normal osteogenesis and to the direct injection and the direct release from the scaffold are compared through the bone homogeneity parameter and elastic modulus.

\section{RESULTS}

The three different type of MagS reported in Tab. I are tested as potential candidates for the magnetic drug delivery strategy for bone healing shown in Fig. 1. The three magnetic scaffolds were analyzed in silico for strengths of the external static magnetic flux density field $\overline{B_{0}}$ ranging from $0.1 \mathrm{~T}$ to $1 \mathrm{~T}$. Moreover, the attraction of the magnetic carriers [17], [18] is investigated.

The magnetic field distribution in the entire analysis domain $\left(\Omega_{1}-\Omega_{3}\right.$ in Fig. 1) resembles the pattern of a uniformly magnetized sphere [20], [24]. The higher the saturation magnetization of the MagS, the higher the maximum amplitude of the magnetic field on the scaffold surface and hence, the magnetic field gradient in the
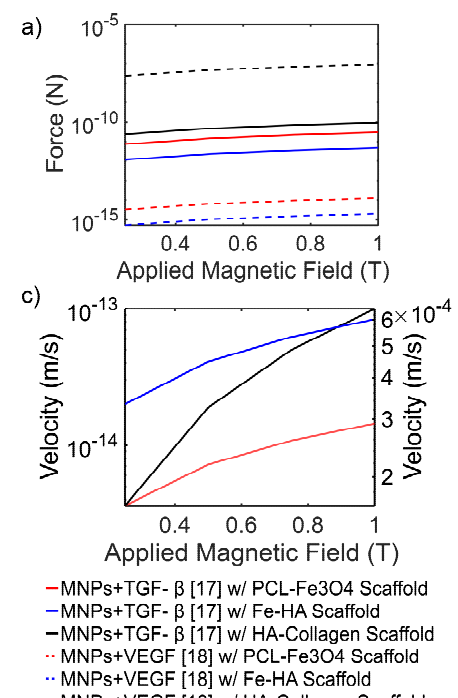

- MNPS+VEGF [18] W/ PCL-Fe3O4 Scaffold
- MNPs+VEGF [18] w/ Fe-HA Scaffold

MNPS+VEGF [18] w/ HA-Collagen Scaffold

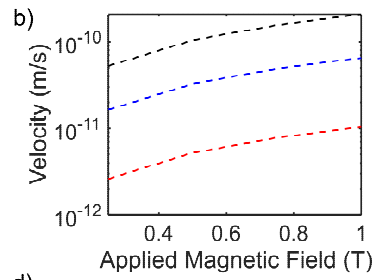
d)

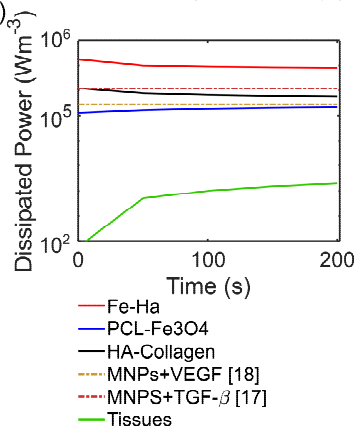

Fig. 4. a) Force exerted from the MagS in Tab. II on the two MDD systems. b) Velocity $\left(\mathrm{ms}^{-1}\right)$ on the MNPs+VEGF [18]. c) Velocity $\left(\mathrm{ms}^{-1}\right)$. d) Dissipated power during the RF-heating step ( $Q_{s c}$ for the MagS in Tab. II, $Q_{m n p}$ for the MDD of [17] and [18], and $Q_{t}$ for biological tissues).

a) $z(\mathrm{~mm})$

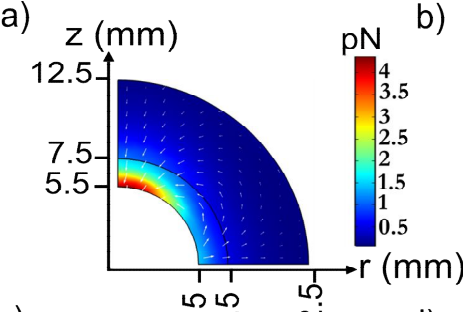

c)

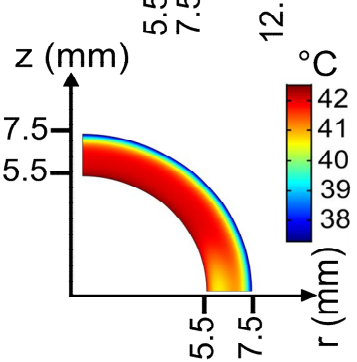

d)
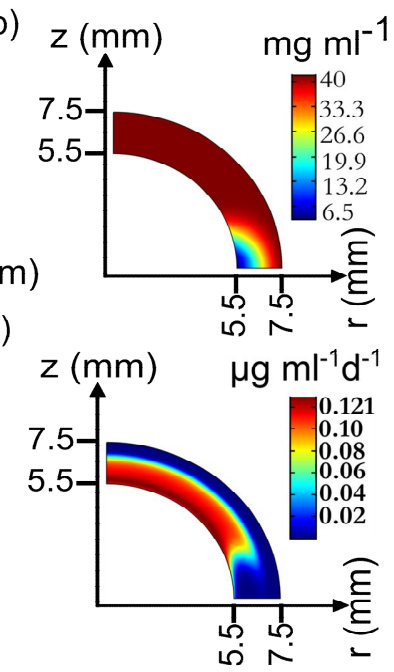

Fig. 5. a) 2D distribution of the magnitude of magnetic force $\left(\overline{F_{m}}\right)$ in the fracture gap and bone. The external magnetic flux density is $0.5 \mathrm{~T}$, the magnetic scaffold is the MHA and the MNPs carrying VEGF are considered. b) Concentration profile $\left(C_{m n p}\right)$ of MNPs+VEGF [18] in the gap, $\left(\mathrm{t}=24 \mathrm{~h}, \mathrm{~B}_{0}=1 \mathrm{~T}\right)$. c) Temperature distribution $(\mathrm{T})$ in the gap after 5 $\mathrm{s}$ for Impregnated HA, MNPs+VEGF [18] exposed to a $30 \mathrm{mT}$ and 293 $\mathrm{kHz}$ magnetic field. d) Pattern of the GF released $\left(\mathrm{R}_{\mathrm{m}, \mathrm{sl}}\right)$ in the gap from the magnetic drug delivery system.

system. By solving Eq. (2), the resulting magnetic force magnitude in the fracture gap is shown in Fig. 5.a. The average intensity of the magnetic force $\overline{F_{m}}$ in the bone and fracture gap is significantly different across the magnetic scaffolds (Fig. 4.a). The higher the magnetization of the scaffold, the stronger the force. Indeed, the ferrofluid impregnated scaffold is the best MagS to be used as attraction platform for MDD [17], [18]. This finding poses an interesting challenge to material science, i.e., the search for a manufacturing method for deriving scaffolds loaded with a high amount of nanoparticles or synthesizing a 
magnetic material with high saturation magnetization. From the physical properties of the MNPs (Tab. II), the nanoparticles carrying the TGF- $\beta$ are bigger and experience a two orders of magnitude higher magnetic force, i.e., hundreds of $\mathrm{pN}$ compared to tens of $\mathrm{pN}$ for the MNPs plus VEGF (Fig. 4.a).

In the viscous fibrin matrix, the velocity impressed to the magnetic carriers is maximum at a magnetic flux density of $1 \mathrm{~T}$ and in the case of impregnated HA (Fig. 4.b and 4.c). Hence, for the modeling of MNPs administration and attraction, the applied magnetic field was set to $1 \mathrm{~T}$. MagS allows to drive the drug transport by the external magnetic field and distributes it according to a controlled gradient [18], [20]. The solutions of Eq.s (4) and (5) presented in Fig. 5.b show that the MNPs concentration in the bone cavity follows the force distribution of Fig. 5.a. Indeed, along the equator of the system $(r, 0)$, it is possible to notice a small depletion region where the magnetic force is minimum. The results for the MDD system with TGF- $\beta$ are qualitatively similar and are not shown. The time of attraction is the same as that measured in similar experimental conditions (i.e., field strength, MNPs size) [58], [59], thus corroborating our numerical findings.

According to Fig. 1, after the attraction, the static field is turned off and the RF magnetic field is applied to the system. After calculating $C_{m n p}$ it is possible to evaluate the spatio-temporal evolution of $Q_{m n p}$. Therefore, the overall dissipated power $Q$ can be estimated (see Fig. 4.d) and the temperature pattern can be computed using the approach from [26], [33]. The three magnetic scaffolds considered in this study present a different heat dissipation dynamic due to the very different type of MNPs embedded in them and due to the volume fraction of the magnetic phase. Using our previous non-linear model [33], we investigate the temporal evolution of power dissipation. From Fig. 4.d, it is possible to notice that the impregnated scaffold has a deposited power which is slightly lower than the other scaffolds. Even if the Impregnated HA scaffolds has a higher content of MNPs, the MHA and Fe-PCL scaffolds contains superparamagnetic nanoparticles which were synthesized to maximize the hyperthermia effect. This step is crucial, since an accurate planning of the time required to reach the release temperature for the GFs would fasten the treatment, while avoiding tissues overheating. With a homogeneous and radial temperature pattern, as shown in Fig. 5.c, the value of $T_{\text {th }}$ is reached within $0.2 \mathrm{~mm}$ from the scaffold surface after 2-5 s, depending on the MDD system. This allows to release the growth factor nearby the biomaterial, as presented in Fig. 5.d, and accelerates the contact osteogenesis.

Having implemented the system of equations for simulating the process in Fig. 1, the analysis is devoted to find suitable values of the dose of the GFs and the proper time of delivery. For an initial dose of $40 \mathrm{ng} \cdot \mathrm{ml}^{-1}$, the MDD release of growth factors is simulated for different stages of
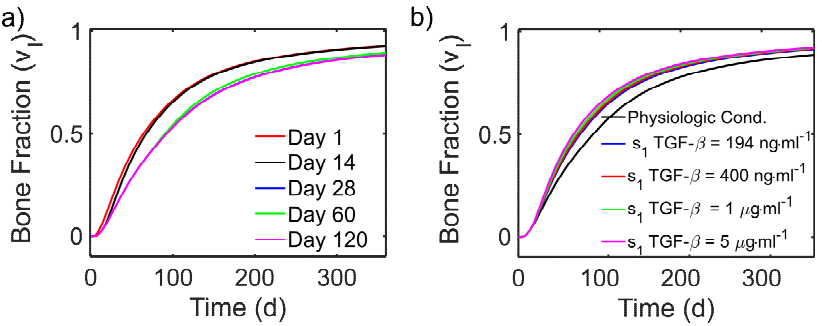

Fig. 6. a) Resulting bone fraction for different administration times. b) Time evolution of the lamellar bone fraction in the fracture gap for different doses of TGF- $\beta$.
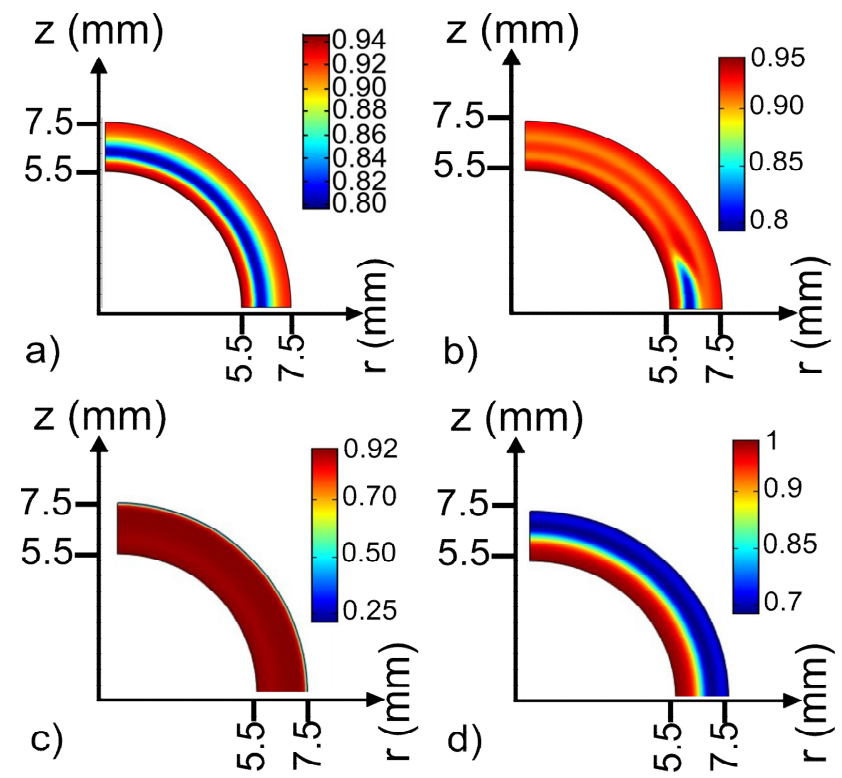

Fig. 7. a) Pattern of the lamellar bone fraction $\left(v_{l}\right)$ at $t=365 \mathrm{~d}$ in the normal healing case. b) The spatial distribution of $\mathrm{v}_{1}$ at $t=365 \mathrm{~d}$ following the magnetic drug delivery treatment using TGF- $\beta$. c) The spatial distribution of $\mathrm{v}_{1}$ at $\mathrm{t}=365 \mathrm{~d}$ when the growth factors are administered by intravenous injection. $d$ ) The spatial distribution of $v_{1}$ at $t=365 d$ when the growth factors are released from the scaffold surface.

TABLE VIII

COMPARISON OF DIFFERENT METHODS OF DRUG DELIVERY OF TGF-B AND VEGF.

\begin{tabular}{ccccc}
\hline \hline & Vl,mean & Vl,std & $\xi$ & $\begin{array}{c}\mathrm{E}, \\
\mathrm{GPa}\end{array}$ \\
\hline Normal healing & 0.9315 & 0.0446 & 20.8856 & 15.95 \\
MagS+TGF- $\beta$ [17] & 0.9447 & 0.0012 & 787.250 & 16.78 \\
MagS+VEGF [18] & 0.9436 & 0.0058 & 162.689 & 16.68 \\
$\quad \begin{array}{c}\text { Direct TGF- } \beta \\
\text { injection }\end{array}$ & 09030 & 0.1627 & 5.5512 & 13.70 \\
$\begin{array}{c}\text { Direct VEGF } \\
\text { injection } \\
\text { TGF- } \beta \text { from } \\
\text { scaffold }\end{array}$ & 0.9015 & 0.1631 & 5.501 & 13.78 \\
$\quad$ VEGF from & 0.8169 & 0.1541 & 5.3011 & 11.04 \\
$\quad$ scaffold & 0.8356 & 0.1502 & 5.5612 & 11.45 \\
\hline \hline
\end{tabular}

the healing process (Fig. 1). From Fig. 6.a, it can be noticed that there is scarce difference (below 1\%) between the administration of MDD at day 1 or 14 day, since the highest bone fraction are obtained. On the other hand, feed the GFs after 14 days, results in a lower fraction of newly formed bone. Therefore, relying on the physiology of bone healing 
process, best time to perform the treatment is within the first 14 days, during the early stage of bone healing (see Fig. 6.a), since the density of MSCs is still high and the differentiation into osteoblastic phenotype is occurring. Hence, simulating an intravenous injection of MNPs at 13 days, different doses of GFs are tested to evaluate the treatment effectiveness. Concentrations of VEGF and TGF$\beta$ from $0.194 \mu \mathrm{g} \cdot \mathrm{ml}^{-1}$ to $5 \mu \mathrm{g} \cdot \mathrm{ml}^{-1}$ are considered. On average, the higher the dose, the higher the final amount of lamellar bone produced in the cavity, as shown in Fig. 6.b. Similar findings holds for the VEGF (data not shown). The maximum difference with the physiological case is more than 5\%. The findings from Fig. 6.b allows us to infer that the proposed mathematical model can be useful for computing the dose and time of administration of GFs through magnetic drug delivery.

The distribution of $v_{l}$ is rather homogeneous when comparing the MagS+MDD case with the normal healing as in Fig. 7.a and Fig. 7.b. From Fig. 7.c., it can be noticed that the intravenous injection allows to reach high value of bone density in the cavity, but there is a thin layer annulus of $\sim 0.1 \mathrm{~mm}$ which present very low value of lamellar bone fraction, in accordance with the experimental findings from [53], [54]. This drawback is due to the burst release of the GF. On the other hand, the drug release from the scaffold ensures the apposition of bone layers from the biomaterial surface. However, far from the implant, as shown in Fig. 7.d, due to the limited spatial influence of the drug release, the new bone density is lower, resulting in poor mechanical properties (see Tab. VII), as found in [55]-[57]. The combined use of magnetic scaffolds and MDD allows to overcome these limitations.

Results from Tab. VIII stress that the treatment using MDD and MagS allows the best bone homogeneity and the highest quality of mechanical properties. The MDD with TGF- $\beta$ is the most effective since tends to $\mathrm{E}_{\max }=18 \mathrm{GPa}$ [60]. In terms of $\xi$, the direct injection of GFs is comparable to the drug release from the scaffold, but the direct injection ensures better mechanical stability of the newly formed bone.

\section{CONCLUSIONS}

This work dealt, for the first time, with the mathematical modeling of magnetic drug delivery of growth factors bone healing and repair. The concept is to implant a magnetic prosthesis and use it as an in situ attraction platform for magnetic nanoparticles carrying bioactive molecules using static magnetic field. Then, the growth factors can be release by increasing the system temperature above a threshold temperature of $42^{\circ} \mathrm{C}$ through radio-frequency heating. The growth factors can then exert a direct action on the adhesion, proliferation and differentiation of osteoprogenitor cells. As a result, the bone repair process can be enhanced. This magnetic drug delivery procedure is a rather non-linear and multiphysic process which call for a specific, innovative mathematical model to study the feasibility and gain, for the first time, an in-depth knowledge about the crucial parameters involved in this tissue engineering strategy.

To this aim, we solved a non-linear magnetostatic problem for computing the field distribution during the exposure to the static magnetic field. Then, the magnetic force exerted on the magnetic carriers is computed. This is already a refinement of the modeling of magnetic scaffolds and this kind of targeted drug delivery [14], [16], [20], [23], [24]. We found that scaffolds with higher saturation magnetization (around $400 \mathrm{kAm}^{-1}$ ) are interesting candidates to be used. Furthermore, we found that the volume and saturation magnetization of the magnetic carriers are also crucial parameters. These findings can indicate and provide useful feedbacks to material scientists.

Then, we investigated the coupling between the magnetostatic problem and the mass transport of the magnetic carriers, in order to predict the spatio-temporal distribution after intravenous injection. Furthermore, we included in the model the microvasculature parameters of the tissue. We found that the concentration profile of MNPs+GFs is strictly connected to the magnetic force profile. We forecast that, if the loading of magnetic scaffolds is not uniform, then relevant limitation to the attraction process or great enhancement could be obtained. This aspect could be of interest for further studies.

The proposed model accounted for the bi-directional coupling between electromagnetic and thermal phenomena during the radio-frequency heating step for the drug release. With our framework, we were able to determine that the presence of the magnetic scaffolds greatly enhances the dissipated power and lower considerably the time required to reach the threshold temperature. The pattern of the releases additional bioactive molecule cannot be easily predicted. Therefore, our model can be regarded as a valuable, unique platform for this case. It can be of interested for researchers working in the field of magnetic fluid hyperthermia with multi-therapeutic nanoparticles.

Finally, slightly modifying a biomathematics model for bone healing [36], we were able to quantify and investigate the direct effects of the magnetic drug delivery strategy for the first time. In this regard, we found that, if performed within the first 14 days of healing and suitable dose, the magnetic drug delivery, compared to physiological healing, to the intravenous injection of growth factors and to the release of biomolecules from the biomaterial (which are traditional drug delivery strategies), stands out in terms of quality of newly formed bone both in homogeneity and mechanical properties.

Therefore, with our numerical experiments we demonstrated that the combined use of magnetic scaffolds and magnetic drug delivery systems for bone repair can be effective. The proposed model may also help in setup validation experiments, under controlled condition, or, even, planning this innovative treatment modality with great advantages for regenerative medicine. Our 
mathematical framework could be used as tool for investigating new type of magnetic carriers and magnetic scaffolds to enhance this therapeutic process, since, from an electromagnetic engineering perspective, it could help in bridging the gap between nanotechnology and biomedicine. Future works must deal with the problem of modeling the angiogenesis using continuum, discrete [61] or multiphase heterogeneous model [62], [63].

\section{REFERENCES}

[1] C. Dahlin, A. Linde, J. Gottlow, and S. Nyman, "Healing of bone defects by guided tissue regeneration." Plastic and reconstructive surgery, vol. 81, no. 5, pp. 672-676, 1988.

[2] A. Lindahl, M. Brittberg, D. Gibbs, J. I. Dawson, J. Kanczler, C. Black, R. Tare, and R. O. Oreffo, "Chapter 16 - cartilage and bone regeneration," in Tissue Engineering (Second Edition), second edition ed., C. A. V. Blitterswijk and J. D. Boer, Eds. Oxford: Academic Press, 2015, pp. 529 - 582. [Online]. Available: http: //www.sciencedirect.com/science/article/pii/B978012420145300016 $\mathrm{X}$

[3] R. A. Perez, S.-J. Seo, J.-E. Won, E.-J. Lee, J.-H. Jang, J. C. Knowles, and H.-W. Kim, "Therapeutically relevant aspects in bone repair and regeneration," Materials Today, vol. 18, no. 10, pp. 573589, 2015.

[4] T. Ghassemi, A. Shahroodi, M. H. Ebrahimzadeh, A. Mousavian, J. Movaffagh, and A. Moradi, "Current concepts in scaffolding for bone tissue engineering," Archives of Bone and Joint Surgery, vol. 6, no. 2, p. 90, 2018.

[5] J. E. Schroeder and R. Mosheiff, "Tissue engineering approaches for bone repair: concepts and evidence," Injury, vol. 42, no. 6, pp. 609$613,2011$.

[6] A. Bagde, A. Kuthe, S. Quazi, V. Gupta, S. Jaiswal, S. Jyothilal, N. Lande, and S. Nagdeve, "State of the art technology for bone tissue engineering and drug delivery," IRBM, 2019.

[7] A. Marino, C. Filippeschi, V. Mattoli, B. Mazzolai, and G. Ciofani, "Biomimicry at the nanoscale: current research and perspectives of two photon polymerization," Nanoscale, vol. 7, no. 7, pp. 28412850,2015

[8] A. M. Ferreira, C. Tonda-Turo, E. Mancuso, and P. Gentile, "Multilayer nanoscale functionalisation to treat disorders and enhance regeneration of bone tissue," Nanomedicine: Nanotechnology, Biology and Medicine, 2019.

[9] F. Serio, M. Miola, E. Vern`e, D. Pisignano, A. R. Boccaccini, and L. Liverani, "Electrospun filaments embedding bioactive glass particles with ion release and enhanced mineralization," Nanomaterials, vol. 9, no. 2, p. 182, 2019.

[10] W. Zhou, J. Um, Y. Zhang, A. P. Nelson, Z. Nemati, J. Modiano, B. Stadler, and R. Franklin, "Development of a biolabeling system using ferromagnetic nanowires," IEEE Journal of Electromagnetics, RF and Microwaves in Medicine and Biology, vol. 3, no. 2, pp. 134-142, 2018.

[11] G. Barrera, M. Cöisson, F. Celegato, E. S. Olivetti, L. Martino, I. Miletto, and P. Tiberto, "Magnetic and thermal characterization of core-shell feoxide@sio 2 nanoparticles for hyperthermia applications," IEEE Journal of Electromagnetics, $R F$ and Microwaves in Medicine and Biology, vol. 2, no. 4, pp. 257-261, 2018.

[12] B. Liang, D. Zuo, K. Yu, X. Cai, B. Qiao, R. Deng, J. Yang, L. Chu, Z. Deng, Y. Zheng et al., "Multifunctional bone cement for synergistic magnetic hyperthermia ablation and chemotherapy of osteosarcoma," Materials Science and Engineering: C, vol. 108, p. 110460,2020

[13] C. Shuai, W. Yang, C. He, S. Peng, C. Gao, Y. Yang, F. Qi, and P. Feng, "A magnetic micro-environment in scaffolds for stimulating bone regeneration," Materials \& Design, vol. 185, p. 108275, 2020.

[14] V. Goranov, T. Shelyakova, R. De Santis, Y. Haranava, A. Makhaniok, A. Gloria, A. Tampieri, A. Russo, E. Kon, M. Marcacci et al., "3d patterning of cells in magnetic scaffolds for tissue engineering," Scientific Reports, vol. 10, no. 1, pp. 1-8, 2020.
[15] O. L. Lanier, A. G. Monsalve, P. S. McFetridge, and J. Dobson, "Magnetically triggered release of biologics," International Materials Reviews, vol. 64, no. 2, pp. 63-90, 2019.

[16] S. Erokhin and D. Berkov, "Magnetic targeted drug delivery to the human eye retina: An optimization methodology," IEEE Journal of Electromagnetics, RF and Microwaves in Medicine and Biology, vol. 3, no. 1, pp. 3-8, 2018.

[17] A. Monsalve, A. C. Bohorquez, C. Rinaldi, and J. Dobson, "Remotely triggered activation of tgf-with magnetic nanoparticles," IEEE Magnetics Letters, vol. 6, pp. 1-4, 2015.

[18] S. Meikle, Y. Pineiro, M. B. Lopez, J. Rivas, and M. Santin, "Surface functionalization superparamagnetic nanoparticles conjugated with thermoresponsive poly (epsilon-lysine) dendrons tethered with carboxybetaine for the mild hyperthermia-controlled delivery of vegf," Acta Biomaterialia, vol. 40, pp. 235-242, 2016.

[19] R. A. Carano and E. H. Filvaroff, "Angiogenesis and bone repair," Drug Discovery Today, vol. 8, no. 21, pp. 980-989, 2003.

[20] N. Bock, A. Riminucci, C. Dionigi, A. Russo, A. Tampieri, E. Landi, V. A. Goranov, M. Marcacci, and V. Dediu, "A novel route in bone tissue engineering: magnetic biomimetic scaffolds," Acta Biomaterialia, vol. 6, no. 3, pp. 786-796, 2010.

[21] A. Tampieri, M. Iafisco, M. Sandri, S. Panseri, C. Cunha, S. Sprio, E. Savini, M. Uhlarz, and T. Herrmannsdoorfer, "Magnetic bioinspired hybrid nanostructured collagen-hydroxyapatite scaffolds supporting cell proliferation and tuning regenerative process," ACS Applied Materials \& Interfaces, vol. 6, no. 18, pp. 15 697-15 707, 2014.

[22] M. Banobre-Lopez, Y. Pineiro-Redondo, M. Uhlarz, A. Tampieri et al., "Magnetic poly ( $\varepsilon$-caprolactone)/iron-doped hydroxyapatite nanocomposite substrates for advanced bone tissue engineering," Journal of the Royal Society Interface, vol. 10, no. 80, p. 20120833 , 2013.

[23] S. K. Samal, V. Goranov, M. Dash, A. Russo, T. Shelyakova, P. Graziosi, L. Lungaro, A. Riminucci, M. Uhlarz, M. BannobreLoopez et al., "Multilayered magnetic gelatin membrane scaffolds," ACS Applied Materials \& Interfaces, vol. 7, no. 41, pp. 23 098-23 $109,2015$.

[24] A. Fanti, M. B. Lodi, and G. Mazzarella, "Enhancement of cell migration rate toward a superparamagnetic scaffold using lf magnetic fields," IEEE Transactions on Magnetics, vol. 52, no. 10, pp. 1-8, 2016.

[25] Q. A. Pankhurst, J. Connolly, S. Jones, and J. Dobson, “Applications of magnetic nanoparticles in biomedicine," Journal of Physics D: Applied Physics, vol. 36, no. 13, p. R167, 2003.

[26] A. Fanti, M. B. Lodi, G. Vacca, and G. Mazzarella, "Numerical investigation of bone tumor hyperthermia treatment using magnetic scaffolds," IEEE Journal of Electromagnetics, RF and Microwaves in Medicine and Biology, vol. 2, no. 4, pp. 294-301, 2018.

[27] J. Meng, B. Xiao, Y. Zhang, J. Liu, H. Xue, J. Lei, H. Kong, Y. Huang, Z. Jin, N. Gu et al., "Super-paramagnetic responsive nanofibrous scaffolds under static magnetic field enhance osteogenesis for bone repair in vivo," Scientific Reports, vol. 3, p. $2655,2013$.

[28] A. D. Grief and G. Richardson, "Mathematical modelling of magnetically targeted drug delivery," Journal of Magnetism and Magnetic Materials, vol. 293, no. 1, pp. 455-463, 2005.

[29] S. J. Kuhn, D. E. Hallahan, and T. D. Giorgio, "Characterization of superparamagnetic nanoparticle interactions with extracellular matrix in an in vitro system," Annals of Biomedical Engineering, vol. 34, no. 1 , pp. $51-58,2006$.

[30] E. V. Rosca and M. R. Caplan, Methods in Bioengineering: Nanoscale Bioengineering and Nanomedicine, K. Rege and I. L. Medintz, Eds. Artech House, Chp. 14, 2009.

[31] R. L. Fournier, Basic Transport Phenomena in Biomedical Engineering. CRC press, 2017.

[32] J. M. Stukel, J. J. Heys, and M. R. Caplan, "Optimizing delivery of multivalent targeting constructs for detection of secondary tumors," Annals of Biomedical Engineering, vol. 36, no. 7, pp. 1291-1304, 2008.

[33] M. B. Lodi, A. Fanti, G. Muntoni, and G. Mazzarella, "A multiphysic model for the hyperthermia treatment of residual osteosarcoma cells in upper limbs using magnetic scaffolds," IEEE Journal on Multiscale and Multiphysics Computational Techniques, 2019.

[34] A. Cervadoro, C. Giverso, R. Pande, S. Sarangi, L. Preziosi, J. Wosik, A. Brazdeikis, and P. Decuzzi, "Design maps for the 
hyperthermic treatment of tumors with superparamagnetic nanoparticles," PloS one, vol. 8, no. 2, p. e57332, 2013.

[35] A. Phillips, "Overview of the fracture healing cascade," Injury, vol. 36, no. 3, pp. S5-S7, 2005.

[36] P. Moreo, J. M. Garcia-Aznar, and M. Doblare, "Bone ingrowth on the surface of endosseous implants. part 1: Mathematical model," Journal of Theoretical Biology, vol. 260, no. 1, pp. 1-12, 2009.

[37] P. Moreo, J. M. Garcia-Aznar, and M. Doblare, "Bone ingrowth on the surface of endosseous implants. part 2: Theoretical and numerical analysis," Journal of Theoretical Biology, vol. 260, no. 1, pp. 13-26, 2009.

[38] J. Baldonedo, J. R. Fernandez, and A. Segade, "Numerical analysis of an osseointegration model," Mathematics, vol. 8, no. 1, p. 87, 2020 .

[39] J. E. Davies, "Bone bonding at natural and biomaterial surfaces," Biomaterials, vol. 28, no. 34, pp. 5058-5067, 2007.

[40] S. M. Slack and T. A. Horbett, The Vroman Effect, 1995, ch. 8, pp. $112-128$.

[41] M. Rabe, D. Verdes, and S. Seeger, "Understanding protein adsorption phenomena at solid surfaces," Advances in Colloid and Interface Science, vol. 162, no. 1-2, pp. 87-106, 2011.

[42] S. M. Perren, "Fracture healing. the evolution of our understanding." Acta Chirurgiae Orthopaedicae et Traumatologiae Cechoslovaca, vol. 75, no. 4, pp. 241-246, 2008.

[43] T. Hillen and K. J. Painter, "A users guide to pde models for chemotaxis," Journal of Mathematical Biology, vol. 58, no. 1-2, p. 183, 2009.

[44] A. Colombi, M. Scianna, and L. Preziosi, "A measure-theoretic model for collective cell migration and aggregation," Mathematical Modelling of Natural Phenomena, vol. 10, no. 1, pp. 4-35, 2015.

[45] Z. Chi, et al. "Detection and Monitoring of Osteoporosis in a Rat Model by Thermoacoustic Tomography." IEEE Journal of Electromagnetics, RF and Microwaves in Medicine and Biology, 2020.

[46] H.-Y. Xu and N. Gu, "Magnetic responsive scaffolds and magnetic fields in bone repair and regeneration," Frontiers of Materials Science, vol. 8, no. 1, pp. 20-31, 2014.

[47] Y. Xia, J. Sun, L. Zhao, F. Zhang, X.-J. Liang, Y. Guo, M. D. Weir, M. A. Reynolds, N. Gu, and H. H. Xu, "Magnetic field and nanoscaffolds with stem cells to enhance bone regeneration," Biomaterials, 2018.

[48] C. Qu, Q.-H. Qin, and Y. Kang, "A hypothetical mechanism of bone remodeling and modeling under electromagnetic loads," Biomaterials, vol. 27, no. 21, pp. 4050-4057, 2006.

[49] M.-A. Lauzon, ' E. Bergeron, B. Marcos, and N. Faucheux, "Bone repair: new developments in growth factor delivery systems and their mathematical modeling," Journal of Controlled Release, vol. 162, no. 3, pp. 502-520, 2012.

[50] F. Mac Gabhann, J. W. Ji, and A. S. Popel, "Computational model of vascular endothelial growth factor spatial distribution in muscle and proangiogenic cell therapy," PLoS Computational Biology, vol. 2, no. 9 , p. e127, 2006.

[51] D. M. Kingsley, "The tgf-beta superfamily: new members, new receptors, and new genetic tests of function in different organisms." Genes \& Development, vol. 8, no. 2, pp. 133-146, 1994.

[52] T. Miura and R. Tanaka, "In vitro vasculogenesis models revisitedmeasurement of vegf diffusion in matrigel," Mathematical Modelling of Natural Phenomena, vol. 4, no. 4, pp. 118-130, 2009.

[53] R. R. Chen, E. A. Silva, W. W. Yuen, and D. J. Mooney, "Spatiotemporal vegf and pdgf delivery patterns blood vessel formation and maturation," Pharmaceutical Research, vol. 24, no. 2, pp. 258-264, 2007.

[54] Y.-I. Chung, S.-K. Kim, Y.-K. Lee, S.-J. Park, K.-O. Cho, S. H. Yuk, G. Tae, and Y. H. Kim, "Efficient revascularization by vegf administration via heparin-functionalized nanoparticle-fibrin complex," Journal of Controlled Release, vol. 143, no. 3, pp. 282289, 2010.

[55] M. B. Keogh, F. J. O'Brien, and J. S. Daly, "A novel collagen scaffold supports human osteogenesis-applications for bone tissue engineering," Cell and Tissue Research, vol. 340, no. 1, pp. 169-177, 2010 .

[56] A. Lode, C. Wolf-Brandstetter, A. Reinstorf, A. Bernhardt, U. Konig, W. Pompe, and M. Gelinsky, "Calcium phosphate bone cements, functionalized with vegf: release kinetics and biological activity,"
Journal of Biomedical Materials Research Part A: An Official Journal of The Society for Biomaterials, The Japanese Society for Biomaterials, and The Australian Society for Biomaterials and the Korean Society for Biomaterials, vol. 81, no. 2, pp. 474-483, 2007.

[57] E. Wernike, M.-O. Montjovent, Y. Liu, D. Wismeijer, E. B. Hunziker, K.-A. Siebenrock, W. Hofstetter, F. M. Klenke et al., "Vegf incorporated into calcium phosphate ceramics promotes vascularisation and bone formation in vivo," Eur Cell Mater, vol. 19, no. 3,2010 .

[58] D. Holligan, G. Gillies, and J. Dailey, "Magnetic guidance of ferrofluidic nanoparticles in an in vitro model of intraocular retinal repair," Nanotechnology, vol. 14, no. 6, p. 661, 2003.

[59] J. Wang, Y. Chen, B. Chen, J. Ding, G. Xia, C. Gao, J. Cheng, N. Jin, Y. Zhou, X. Li et al., "Pharmacokinetic parameters and tissue distribution of magnetic fe3o4 nanoparticles in mice," International journal of nanomedicine, vol. 5, p. 861, 2010.

[60] H. H. Bayraktar, E. F. Morgan, G. L. Niebur, G. E. Morris, E. K. Wong, and T. M. Keaveny, "Comparison of the elastic and yield properties of human femoral trabecular and cortical bone tissue," Journal of Biomechanics, vol. 37, no. 1, pp. 27-35, 2004.

[61] M. Scianna, C. Bell, and L. Preziosi, "A review of mathematical models for the formation of vascular networks," Journal of Theoretical Biology, vol. 333, pp. 174-209, 2013.

[62] A. Chauviere, T. Hillen, and L. Preziosi, "Modeling cell movement in anisotropic and heterogeneous network tissues," Networks and Heterogeneous Media, vol. 2, no. 2, p. 333, 2007.

[63] L. Preziosi and A. Tosin, "Multiphase modelling of tumour growth and extracellular matrix interaction: mathematical tools and applications," Journal of Mathematical Biology, vol. 58, no. 4-5, p. $625,2009$.

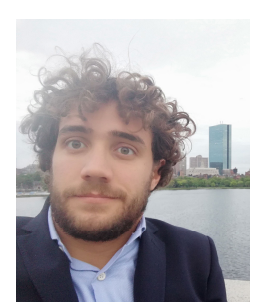

Matteo Bruno Lodi (S'19) was born in Cagliari January 15, 1994. He achieved the Bachelors' degree in Biomedical Engineering in 2016 at University of Cagliari and received the Master' degree in Biomedical Engineering from Politecnico di Torino in 2018. He is currently a PhD candidate in Electronic Engineering and Computer Science at the University of Cagliari. His research activity deals with the modeling of bioelectromagnetic phenomena, the study, manufacturing and synthesis of magnetic biomaterials for tissue engineering applications and the use of microwave for biotechnology and environmental applications. He was awarded as Young Scientists at the General Assembly and Scientific Symposium of URSI 2020. He serves as Topic Editor for Electronics (MDPI). He has been appointed as Representative for the Young Professionals of IEEE Region 8 Nanotechnology Council. He is a member of the Editorial Board of the IEEE Future Directions Technology Policy and Ethics newsletter.

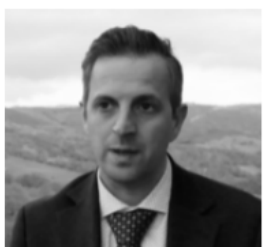

Alessandro Fanti received the Laurea degree in electronic engineering and Ph.D. degree in Electronic Engineering and computer science from the University of Cagliari, Cagliari, Italy, in 2006 and 2012, respectively. He worked as postdoctoral fellow in the Electromagnetic Group at the University of Cagliari from 2013 to 2016, where he is currently an Assistant Professor. His research activity involves the use of numerical techniques for modes computation of guiding structures, optimization techniques, analysis and design of waveguide slot arrays, analysis and design of patch antennas, radio propagation in urban environment, modelling of bio-electromagnetic phenomena, microwave exposure systems for biotechnology and bio-agriculture. Dr. Alessandro Fanti is an Associate Editor of IEEE Journal of Electromagnetics, RF and Microwaves in Medicine and Biology (J-ERM).

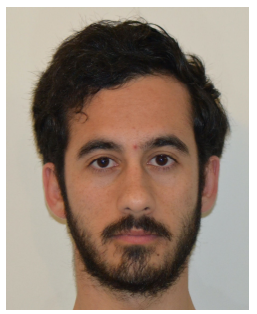

Andrea Vargiu received the Bachelor degree in Biomedical Engineering in 2019 from the University of Cagliari. $\mathrm{He}$ is currently involved in the mathematical 
modeling of magnetic biomaterials for tissue engineering and drug delivery applications.

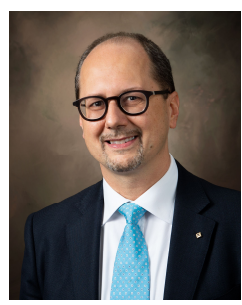

Maurizio Bozzi (Fellow, IEEE) S'98-M'01SM'12-F'18) received the Ph.D. degree in electronics and computer science from the University of Pavia, Pavia, Italy, in 2000. In 2002, he joined the Department of Electronics, University of Pavia, where he is currently a full professor of electromagnetic fields. He held research positions with various universities worldwide, including the Technische Universität Darmstadt, Germany; the Technische Universität Darmstadt, Germany; the Universitat de Valencia, Spain; and the École Polytechnique de Montréal, Canada. He was also a Guest Professor at Tianjin University, China (2015-2017) and a Visiting Professor at Gdansk University of Technology, Poland (2017-2018). He has authored or co-authored more than 140 journal papers and 330 conference papers. He co-edited the book Periodic Structures (Research Signpost, 2006) and co-authored the book Microstrip Lines and Slotlines (Artech House, 2013). His main research interests concern the computational electromagnetics, the substrate integrated waveguide technology, and the use of novel materials and fabrication technologies for microwave circuits.

Prof. Bozzi is an Elected Member of the Administrative Committee of the IEEE Microwave Theory and Techniques Society (MTT-S) for years 2017-2022 and the current MTT-S Treasurer. He was the Chair of the Meetings and Symposia Committee of MTT-S AdCom for years 20182019, the Secretary of IEEE MTT-S for year 2016, and a member of the General Assembly (GA) of the European Microwave Association (EuMA) for the term 2014-2016. He is a Track Editor of the IEEE TRANSACTIONS ON MICROWAVE THEORY AND TECHNIQUES. He was an Associate Editor of the IEEE MICROWAVE AND WIRELESS COMPONENTS LETTERS, IET Electronics Letters, and IET Microwaves, Antennas and Propagation. He was the Guest Editor of special issues in the IEEE TRANSACTIONS ON MICROWAVE THEORY AND TECHNIQUES, the IEEE MICROWAVE MAGAZINE, and the IET Microwaves, Antennas and Propagation. He was the General Chair of the IEEE MTT-S International Microwave Workshop SeriesAdvanced Materials and Processes (IMWS-AMP 2017), in Pavia, Italy, 2017, of the inaugural edition of the IEEE International Conference on Numerical Electromagnetic Modeling and Optimization (NEMO2014), in Pavia, Italy, 2014, and of the IEEE MTT-S International Microwave Workshop Series on Millimeter Wave Integration Technologies, in Sitges, Spain, 2011.

He received several awards, including the 2015 Premium Award for Best Paper in IET Microwaves, Antennas \& Propagation, the 2014 Premium Award for the Best Paper in Electronics Letters, the Best Student Paper Award at the 2016 IEEE Topical Conference on Wireless Sensors and Sensor Networks (WiSNet2016), the Best Paper Award at the 15th Mediterranean Microwave Symposium (MMS2015), the Best Student Award at the 4th European Conference on Antennas and Propagation (EuCAP 2010), the Best Young Scientist Paper Award of the XXVII General Assembly of URSI in 2002, and the MECSA Prize of the Italian Conference on Electromagnetics (XIII RiNEm), in 2000.

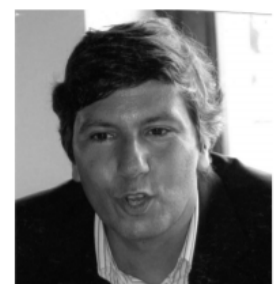

Giuseppe Mazzarella (S'82, M'90, SM'99) graduated Summa with Laude in Electronic Engineering from the Università Federico II of Naples in 1984 and subsequently obtained the Ph.D. in Electronic Engineering and Computer Science in 1989. In 1990 he became Assistant Professor at the Dipartimento di Ingegneria Elettronica at the Università Federico II of Naples. Since 1992 he is with the Dipartimento di Ingegneria Elettrica ed Elettronica of the Università di Cagliari, first as associate professor and then, since 2000, as full professor, teaching courses in Electromagnetics, Microwave, Antennas and Remote Sensing. His research activity has focused mainly on efficient design of large arrays of slots, power synthesis of array factor, with emphasis on inclusion of constraints, microwave holography techniques for the diagnosis of large reflector antennas, use of evolutionary programming for the solution of inverse problems, in particular problems of synthesis of antennas and periodic structures. He is author (or coauthor) of over 70 papers in international journals, and is a reviewer for many EM journals. 